\title{
Assessment of small hydropower potential by software. Case study
}

\author{
Alexandru Moldoveanu ${ }^{1}$, and Daniela Popescu ${ }^{2, *}$ \\ ${ }^{1}$ National Institute of Hydrology and Water Management, Water Management Department, 97 \\ Bucuresti - Ploiesti, Bucharest, 013686, Romania \\ ${ }^{2}$ Technical University Gheorghe Asachi of Iași, Department of Fluid Mechanics, Fluid Machinery and \\ Fluid Power Systems, B-dul Dimitrie Mangeron nr.59A, Iasi, 700050, Romania
}

\begin{abstract}
The rivers hydropower potential is considered one of the oldest renewable energy source used in the electricity production process. A method to investigate the possibility to construct a micro hydropower system on a small river is presented. The analysis and the hydropower assessment were done by using Vapidro-Aste software. Results point out that micro-hydro units can be implemented in remote locations or hybrid renewable energy systems, while the environmental flow is guaranteed.
\end{abstract}

\section{Introduction}

The European Union vision regarding the policy in the field of energy is defined by the sustainable development concept. This concept represents a major challenge for the European Union and especially for ensuring energy security with clean energy at competitive prices for the population and also taking into consideration the increasing global energy demand. By the ratification of the Kyoto Protocol, the European Member States committed to achieve the objectives on reducing the greenhouse gas emissions. One of the first measures performed at the European level was the development of a unique energy trade market and the promotion of electricity produced from renewable energy sources.

In this frame, the European Commission issued the Directive 2009/28/CE on the promotion of the use of energy from renewable sources and its main objective is that $20 \%$ from the total internal gross consumption of energy for each Member State must be produced from renewable energy sources until 2020 [1]. In the Directive 2009/28/CE acceptance, only the small hydropower potential developed in hydropower plants with an installed capacity smaller than $10 \mathrm{MW}$ can be considered a renewable source of energy for generating electricity.

New energy policies boosted the study of micro-power (up to $100 \mathrm{~kW}$ ) and pico scale hydropower (up to $5 \mathrm{~kW}$ ), as a research direction worthy of investigation. Micro or pico hydro turbines can be used as standalone installations or as part of small hybrid renewable energy systems (HRES), that combine wind turbines, photovoltaic modules, micro-hydro and biomass units [2], [3]. They can be installed with minimum construction costs on rivers

${ }^{*}$ Corresponding author: daniela_popescu@tuiasi.ro 
that have low heads and fluid flow rates. In this situation, only several types of turbines are recommended, the cross flow turbine, the Archimedean screw and the Kaplan microturbine.

In this paper a method to investigate the possibility to construct a micro hydropower system on a small river is presented. A case study, the Topolog river, is in focus. The method is based on the Vapidro-Aste software to identify the best way to use the hydraulic potential, characterized by low head and low fluid flow rates. The method takes into consideration an important restriction; part of the fluid flow rate cannot be used to produce electricity, because it must be discharged to protect the river ecosystem. The environmental flow takes into account the natural variability of the flow regime and describes the quantity and quality of water flows required to protect aquatic ecosystems of the rivers. In this study, it was taken into consideration according to the Water Framework Directive 60/2000/EC provisions for the environmental objectives achievement regarding environmental flow downstream the hydropower plant [4].

The results of the complex analysis indicate that a cross-flow turbine is recommendable in the studied case.

\section{Vapidro-Aste software presentation}

Vapidro - Aste is a software for the assessment of small hydropower potential. The Vapidro-Aste was developed at the same time as the GIS (Geographic Information System) spreading utilization all over the world, preserving the software developers trend to use GIS as an interface. It was developed by the Italian Lead Partner RSE S.p.A., within the SEE HYDROPOWER project [5-6], financed in the frame of the South East Europe Programme.

The main steps for applying Vapidro - Aste are: loading a DTM (Digital Terrain Model), introducing the hydrological and technical data, introducing the financial and economic data and performing the analysis of the river selected for the assessment of the small hydropower potential [7].

The main hydrological and technical input data are the following:

- the mean flow of the analyzed river sector (in one to four cross sections);

- the environmental flow;

- the withdrawals and restitutions along the analyzed river sector;

- hydropower efficiency coefficients.

After introducing the DTM (Digital Terrain Model) the Vapidro - Aste is able to generate the river network on the selected area. The following steps consist of introducing the required data mentioned above and performing the technical analysis.

The main economic and financial data are the following:

- the updating interest rate;

- the plant lifetime;

- the price of the energy produced;

- the price of the green certificates needed.

After introducing the economic and financial data, the Vapidro - Aste is able to perform the economic analysis.

The main outcomes of the Vapidro - Aste are the following:

- the automatic river network generation and sub-basin computation;

- $\quad$ the gross and net heads distribution along the analyzed river sector;

- $\quad$ the hydropower potential distribution (the maximum installed capacity) along the analyzed river sector;

- the distribution of the mean annually energy production corresponding to the mean annually operating hours of the small hydropower plant; 
- the optimal number of small hydropower plants for the analyzed river sector;

- the most suitable locations for the water abstractions and the small hydropower facilities placed on GIS maps for the analyzed river sector development scheme.

\section{Case study. Topolog River}

The Topolog River is a tributary of the Olt River and has a length of $111 \mathrm{~km}$ with a river basin area of $543 \mathrm{~km}^{2}$ [8]. The Topolog River springs are located under the Negoiu Peak $(2535 \mathrm{~m})$ and the river presents the typical characteristics of the Southern Carpathians Rivers. The river forms after the confluence of two streams springing from the glacial cirques, the Negoiu and Scara streams, the first being considered its ancestor $(1880 \mathrm{~m})$. In the upper part of the river or upstream of the Capul Bulzului, the river has slopes of 45 $\mathrm{m} / \mathrm{km}$ and the valley was being shaped in the crystalline schists with frequent injections of gneiss, which leads to the development of the selective erosion [9]. In figure 1, the cartographic representation of the Topolog and Olt River Basins is presented.
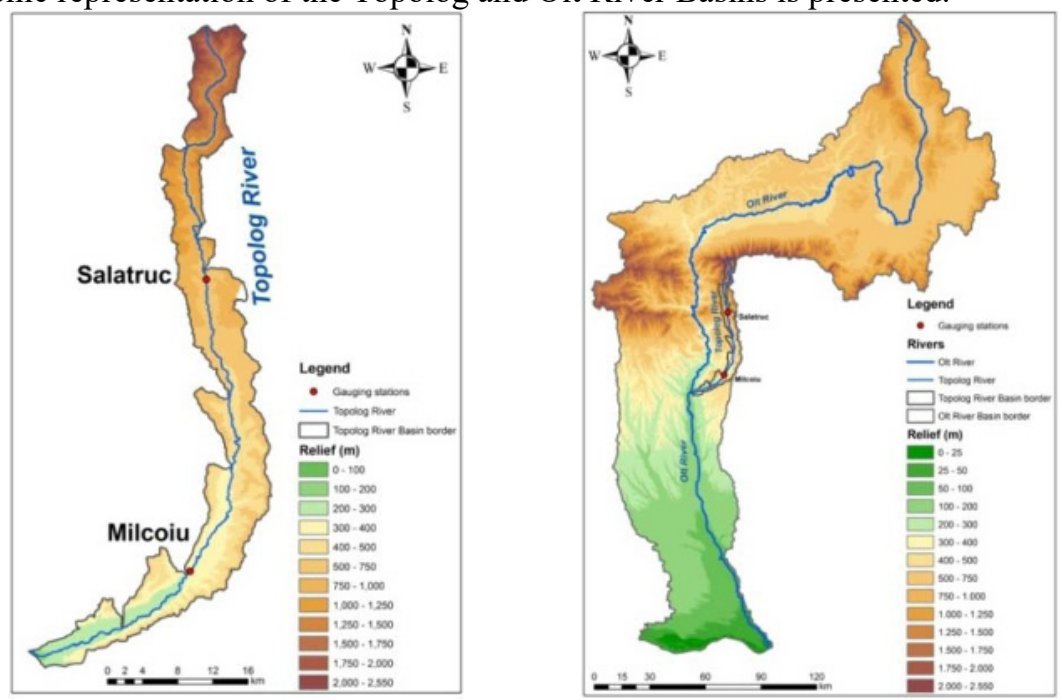

Fig. 1. The cartographic representation of the Topolog and Olt River Basins.

\subsection{The selected methodology and the input data used}

Along the Topolog River, a sector with the length of $34 \mathrm{~km}$ was selected by Vapidro - Aste and represents the river sector from its springs to the Salatruc gauging station.

The selected methodology, a single small hydropower plant with diversion, was considered for a single environmental flow downstream of the water works corresponding to a single hydrological mean flow and without abstractions and restitutions along the selected river sector.

In the next step the following input data were used:

- the mean flow $\left(\mathrm{Q}_{\text {mean }}=1.27 \mathrm{~m}^{3} / \mathrm{s}\right)$ at the Salatruc gauging station;

- the environmental flow $\left(Q_{\text {env }}=0.2 \mathrm{~m}^{3} / \mathrm{s}\right)$;

- the hydropower efficiency coefficients required by the Vapidro - Aste main menu.

In this hypothesis, the economic and financial data was not taken into consideration and the economic analysis was not performed, due to the fact that the future micro hydropower unit is planned to be used only for private purposes and will not be connected to the national energy grid. 


\subsection{The results of the Vapidro - Aste application on the selected river sector}

After performing calculations, the software associates a series of river sub-basins to the river sector analyzed that represent the river catchment. Then, the Vapidro - Aste correlates these results with the data extracted from the digital terrain model (DTM) resulting head (the height difference between two sections of calculus) which is presented in Figure 2 as a map and as a graph.

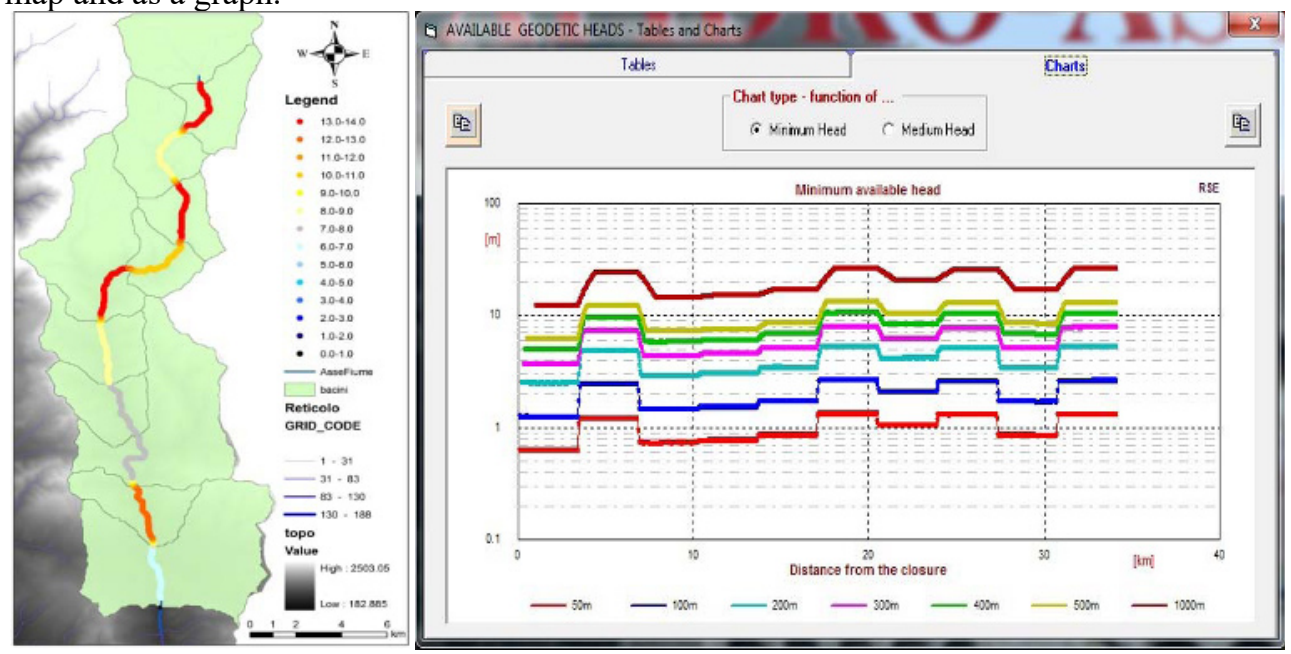

Fig. 2. The representation of the heads distribution along the analyzed river sector

The hydropower potential assessment of the analyzed river sector was performed based on the heads and the optimum installed capacity which was calculated based on the input data mentioned above. The distribution of the maximum installed capacity is presented in Figure 3 as a map and as a graph.

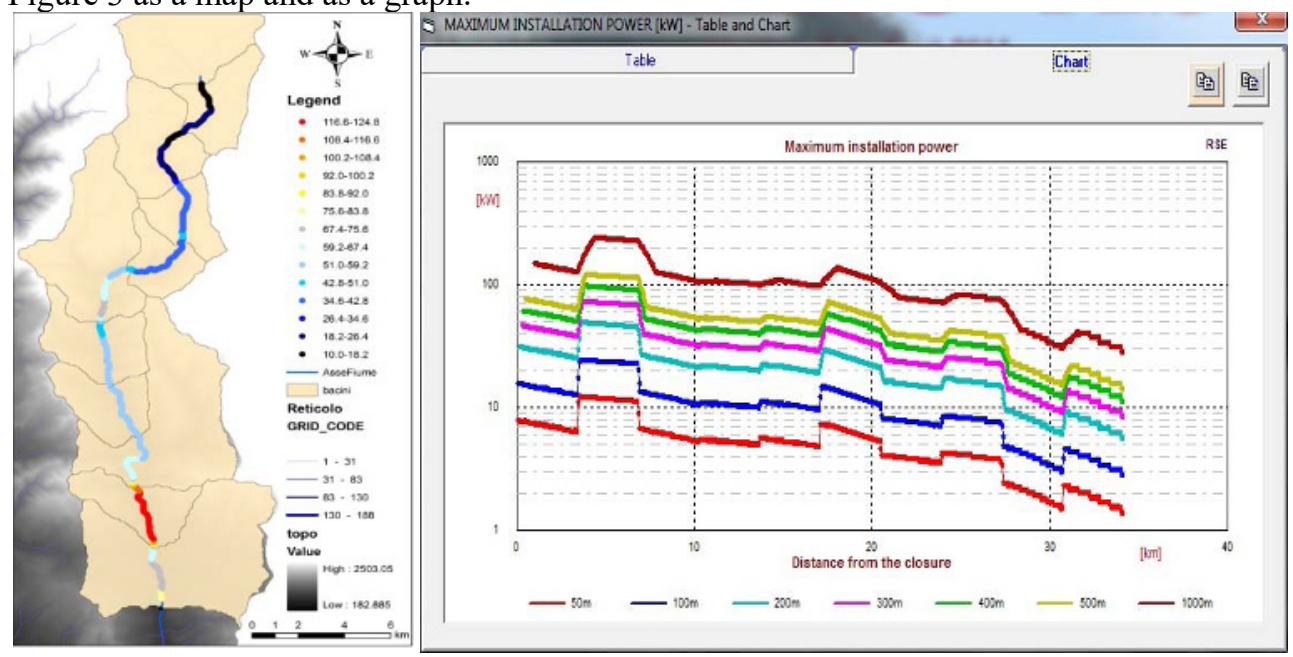

Fig. 3. The representation of the installed capacity distribution along the analyzed river sector

In the presented case study, the optimum installed capacity on the analyzed river sector resulted from calculus is $22 \mathrm{~kW}$ and the mean electricity production computed for an operation time of the hydropower unit of 4632 hours/year is about $102 \mathrm{MWh} /$ year. The distribution of the mean electricity production corresponding to the operation hours of the hydropower system within a year is presented in Figure 4 as a map and as a graph. 


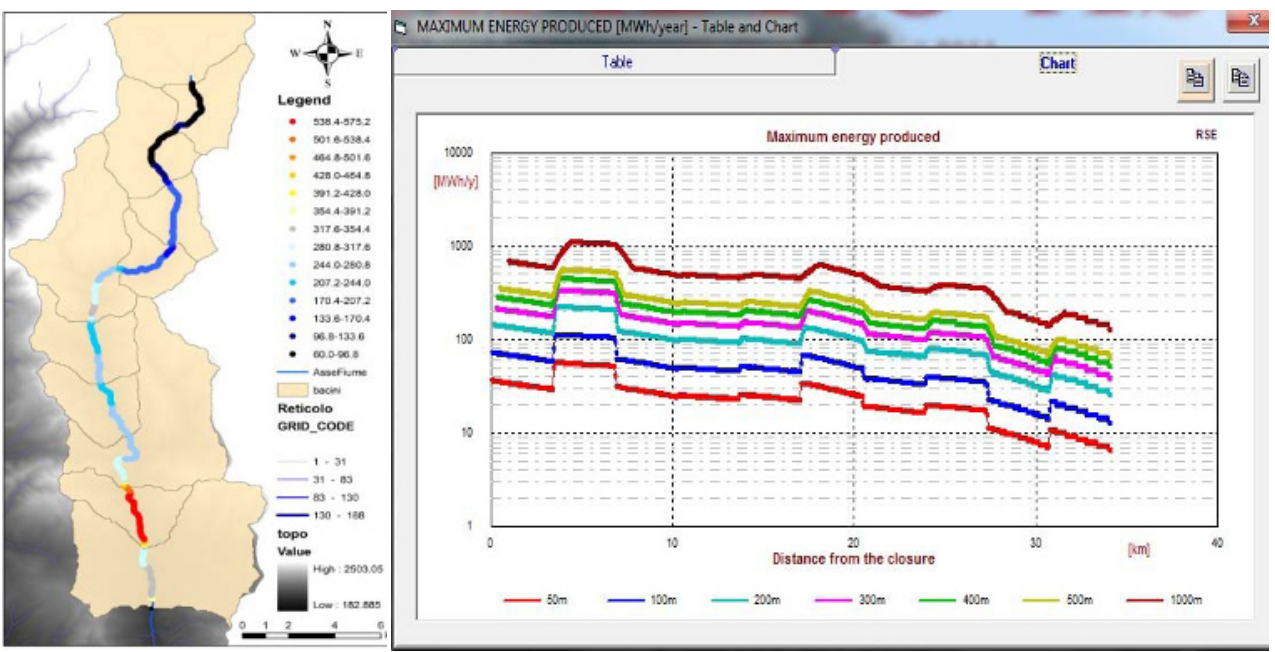

Fig. 4. The mean electricity production distribution representation along the analyzed river sector

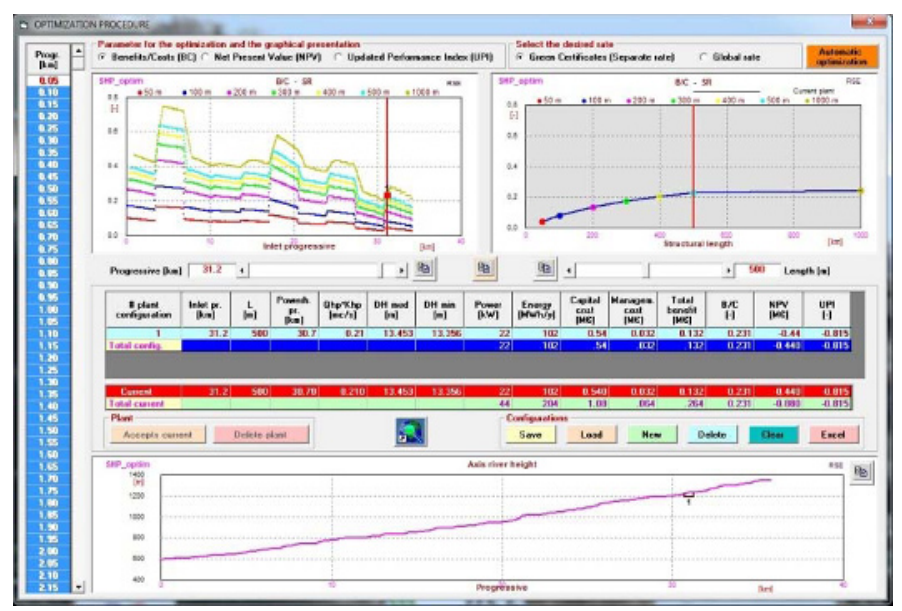

Fig. 5. The result of the automatic/manual function of the Vapidro - Aste
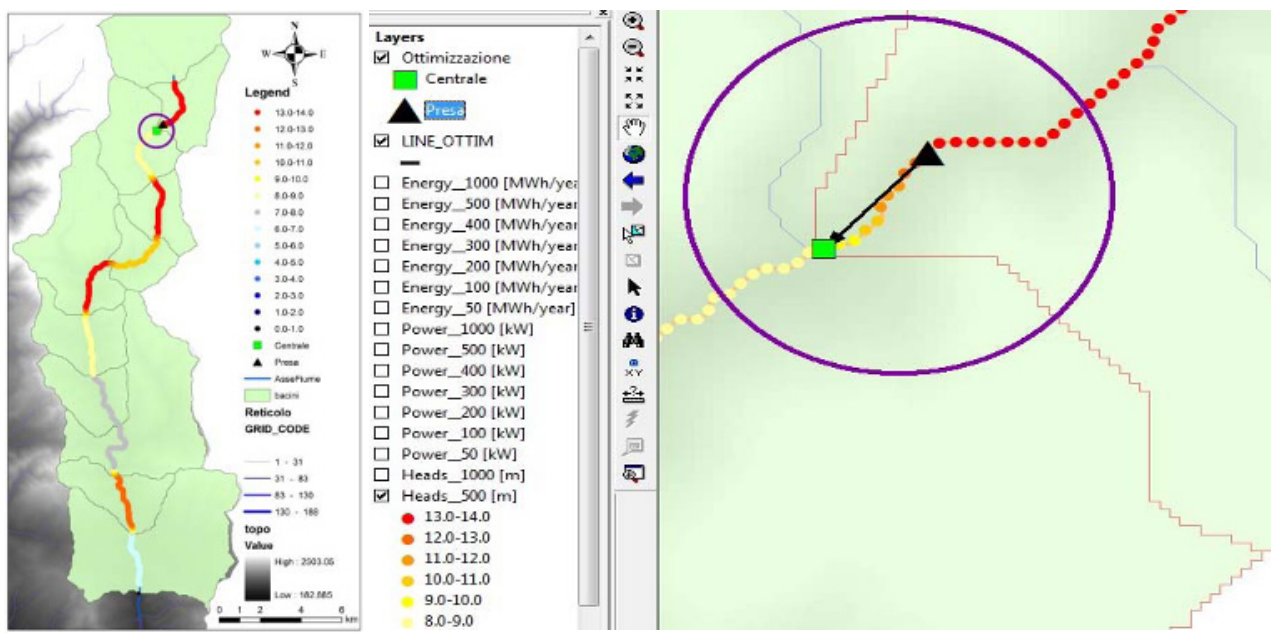

Fig. 6. The cartographic representation of the optimized location of the micro - hydropower unit. 
The optimal distance between the water intake and the micro-hydro facility location is the result of the automatic/manual procedure of the Vapidro - Aste software. For this study, the resulted length of the manual procedure is about 500 meters and the optimal locations for the water intake and the micro-hydro power unit, from the technically point of view are presented above in Figure 5 and in Figure 6.

\section{Conclusions}

The optimal distance between the water intake and power plant location and their optimal positions along the river sector, represent relevant information for potential investors in the field of small hydropower plants construction.

Every potential site must be analyzed case by case and the Vapidro - Aste application represents only a preliminary stage for the suitable sites identification in order to build a new micro hydropower system.

In the present case study, the results revealed that the optimum installed power on the analyzed river sector is $22 \mathrm{~kW}$, which corresponds to a distance of 500 meters from the water intake to the micro turbine and for a mean head of 13-14 meters. In this case, a cross flow turbine is recommended. The mean electricity production is about $102 \mathrm{MWh} /$ year and is computed for an operation time of the hydropower unit of 4632 hours/year.

The results took into consideration the environmental flow to the hydropower assessment of the analyzed river and were presented both as GIS maps, as well as graphics.

Concluding, micro-hydro units can be implemented in remote locations or hybrid renewable energy systems, without a significant risk of impact on the river ecosystem.

The paper contributes to achieving the objectives and highlights the results of the research project "Cross Flow Hydro Turbines for Pico Renewable Energy Systems", contract 45/1.07.2014, financed by the Romanian Executive Agency for Higher Education, Research, Development and Innovation Funding (UEFISCDI) in the frame of the research program Partnerships in Priority Domains - PN II, project code PN-II-PT-PCCA-2013-4-1901.

The VAPIDRO-ASTE software has been used. It has been produced by RSE S.p.A in the frame of the SEE HYDROPOWER project financed by the South East Europe Program and the Research Fund for the Italian Electrical System [5-7].

\section{References}

1. European Council, Directive 2009/28/EC on the promotion of the use of energy from renewable sources, amended by Directive 2013/18/EU (2009)

2. S. Meshram, G. Agnihotri, S. Gupta, JRSE 6, 013140 (2014)

3. A. Afshin, M. Angelo, A. Pedrasa, TENCON 2012-IEEE Region 10 Conference, 10.1109/TENCON.2012.6412230 (2012)

4. European Council, Water Framework Directive 2000/60/EC with further amendments (2000)

5. M. Peviani, J. Alterach, A. Danelli, SEE HYDROPOWER Project, targeted to improve water resource management for a growing renewable energy production, HYDRO 2011, Praha October 17-19 (2011)

6. http://www.seehydropower.eu/

7. J. Alterach, A. Elli, M. Vergata, SEE Hydropower -VAPIDRO ASTE 4.0 User Guide. WP 5 - Common strategies to improve SHP Implementation (2012)

8. Ministry of the Environment, Cadastral Water Atlas of Romania (in Romanian) (1992)

9. I. Ujvary, Geography of Romania's waters (in Romanian) (Editura Științifică, Bucuresti,1972) 